\title{
Social Media vs. Traditional Internet Use for Community Involvement: Toward Broadening Participation
}

\author{
Andrea Kavanaugh ${ }^{1}$, John C. Tedesco ${ }^{2}$, and Kumbirai Madondo 3 \\ ${ }^{1}$ Virginia Tech, Computer Science Department, USA \\ ${ }^{2}$ Communication Department, USA \\ ${ }^{3}$ Sociology Department, USA \\ \{kavan, tedesco, kmadondo\} @vt. edu
}

\begin{abstract}
Education has consistently been the main predictor of political and civic engagement in offline and traditional Internet (i.e., email and web browsing) contexts in the US. Prior research suggests that the same 'more educated, extroverted, and activist' type of individuals (i.e., similar to opinion leaders) continued to be more engaged in civic affairs regardless of offline or online context. That is, the advent of Internet access and use did not fundamentally change the pattern of civic engagement in the US. With social media, however, the correlation between education and civic engagement may be less strong. Social media (e.g., social network sites like Facebook or MySpace, blogs and micro-blogs like Twitter, and photo and video sharing sites like Flickr and YouTube) are able to leverage offline social networks online to enable information and idea sharing among trusted sources about civic issues and concerns. In this paper we report findings from a 2012 survey of residents in the geographic community of Blacksburg, Virginia and environs. The main implication of our findings is that social media use for civic purposes is less strongly associated with and predicted by education and extroversion. As such, social media may represent a breakthrough in broadening community involvement.
\end{abstract}

Keywords: Digital government, community engagement, civic participation, Internet, social media.

\section{Introduction}

Education consistently has been the main predictor of political and civic engagement in offline and traditional Internet contexts (i.e., email and web browsing). Prior research on the use of traditional Internet for civic purposes suggests that the 'more educated, extroverted, and activist' type of individuals (i.e., opinion leaders) continued to be more engaged in civic affairs regardless of offline or online context. However, the use of social media for civic purposes may be less strongly correlated with education, as well as activism and extroversion. Social media (e.g., social network sites like Facebook or MySpace, blogs and micro-blogs like Twitter, and photo and 
video sharing sites like Flickr and YouTube) are able to leverage offline social networks online to enable information and idea sharing among trusted sources about civic issues and concerns.

We report here findings from a 2012 survey of residents in the geographic community of Blacksburg, Virginia and surrounding Montgomery County in southwest Virginia. Located in the foothills of the Allegheny Mountains in Appalachia, Blacksburg and Montgomery County are home to the land grant university, Virginia Tech, and the community computer network known as the Blacksburg Electronic Village (BEV) that established Internet access for the public in this geographic area in 1993. The Blacksburg Electronic Village (BEV) was an early leader (1993-96) in community computer networking simply by making the Internet accessible and by training and supporting users, including residents, government, businesses, community groups, public schools and libraries. Since those early Internet years, though, the vast majority of Americans (79\%) have adopted the Internet, as have most organizations [1]. Our findings from earlier studies of Internet effects on community involvement for Blacksburg and environs have been replicated in similar middle class US localities, including PrairieNet in Champaign-Urbana, Illinois, the Seattle Community Network in Seattle, Washington, and Three Rivers FreeNet in Pittsburgh, Pennsylvania [2]. Most US cities currently have a variety of locally oriented content online for community organizations, government, and neighborhoods [3]. Blacksburg and environs are still somewhat ahead of other communities on Internet penetration rates, but we are confident that findings from our investigation will continue to generalize to similar middle class towns and mixed rural areas. To the extent that Blacksburg is advanced in its use of social software [4] the results of our work will continue to contribute to community computing and political participation research.

\section{Theoretical Background and Justification}

Political participation theories, and most research findings on influences of civic and political participation, generally find that education is the main predictor of participation, albeit sometimes in association with political efficacy, information access, group membership and community attachment [15, 16, 17, 18, 19, 20, 21, 22]. Kavanaugh and colleagues modeled the influence of education, extroversion, and age (as external variables), and the influence of local group membership, staying informed, community collective efficacy and activism (as mediating variables) on the use of traditional Internet for civic purposes [23]. Well-educated, extroverted, informed activists with multiple group memberships (that is, essentially opinion leaders) become more involved in local community issues when they go online. Thus, traditional Internet has tended to reinforce the engagement of people who were already engaged.

In addition to education, as noted above, other variables that influence political participation include political efficacy, information access, group membership and community attachment. Along with extroversion, these variables describe opinion leaders, the $10-15 \%$ of any population who are early innovation adopters and informal 
(and sometimes formal) sources for advice and recommendations to others in their social network and beyond. While opinion leaders are political active, not all political activists are opinion leaders.

A number of studies on social networks have argued that political discussion networks play a crucial role in the democratic process because they give citizens the opportunity to engage in political talk and access to conflicting ideas [24, 25]. Some scholars have emphasized the importance of political talk as a precursor to political participation [26, 27]; although others have disputed this emphasis [28]. Since social media enable a rich type of interpersonal dialogue and deliberation among members of a social network, online political discussion networks can be wider and deeper than the networks generated by other types of discussion [25].

We have collected and analyzed household surveys for almost two decades (1993-2012) in Blacksburg and environs. Our results have showed a clear trend indicating that traditional Internet use (i.e., email and web browsing) for civic and political purposes has been predicted by education, extroversion, age (middle age), community group membership, collective efficacy and activism [19,20],[13]. These are also among the key defining characteristics of opinion leaders. Thus, traditional Internet use tends to reinforce the long established pattern of more educated and active members of a community using email and web browsing for greater political and civic participation.

The effects of Internet use for civic and political purposes include increased awareness and knowledge of issues, greater sharing of information and heterogeneity of discussion networks, and increased community involvement [19,20,21,22]. But if these effects only reinforce prior social patterns of involvement, traditional Internet services are primarily increasing the participation of previously more active members of a community. We have also found in our prior studies a slight increase in the involvement of those "slightly less politically active but still interested in the community". In this paper we report on findings comparing predictors of traditional Internet use for civic purposes with predictors of social media use for civic purposes. We find similar effects but for a broader, more diverse population due possibly to the game-changing nature of social media.

Our study is inspired by the preliminary finding by Smith and colleagues [10] that the use of social media (social network sites, blogs, micro-blogs) for civic purposes is not as strongly associated with socio-economic status (SES), measured by education and income, as traditional Internet use (e.g., email and web browsing).This is very important to our work. Another relevant finding from a study of blog readers asserts that participation in online discussion was predicted by education, but not in the direction traditionally found in research [23]. "Instead, it is those with less education who demonstrate more online expressive participation," (p. 46) in blogs. This suggests that web logs (i.e., blogs) may provide a pathway to political discussion and civic participation among those typically less politically active, the silent majority, and possibly the politically disillusioned and disengaged from conventional politics.

In our study results reported here, we expand on our prior (2005) model of the civic effects of Internet use [13] that seeks to explain the influence of exogenous and 
intermediating variables on respondents' self-reported level of community involvement since getting on the Internet. In this paper, we re-tested and compared this earlier model with social media use variables to assess their influence on civic engagement. We test the following hypotheses: 1) younger adults are using social media for civic purposes more than older adults; 2) social network factors, such as group membership, will be a stronger predictor of using social media for social purposes than 'staying informed' and 'activism'; and 3) the use of social media for civic purposes is less strongly correlated to education than the use of traditional Internet for civic purposes. Our empirical study should provide an important comparison with earlier studies as well as with our own prior results [24, 25, 26, 27].

The area of Blacksburg, Virginia and environs offers a rich opportunity to investigate the effects of Internet vs. social media use on community involvement. The majority (about 85\%) of Blacksburg residents (population roughly 42,000 in 2010) are affiliated as faculty, staff, or students with the land grant university known as Virginia Tech. The neighboring town of Christiansburg (with a population of about 21,000 ) and Blacksburg lie within rural Montgomery County (population almost 95,000), governed by a Board of Supervisors that has jurisdiction over such services as the school district and public libraries, and some shared infrastructures, such as transportation and roads. While Blacksburg tends to be slightly above the national average in socio-economic status (as measured by education and income), in terms of Internet and social media penetration, the town of Christiansburg and the rest of Montgomery County are similar to national penetration rates on these measures. The study results reported here are from households throughout Montgomery County, including Blacksburg and Christiansburg.

\section{Methods}

We used purposeful sampling and combined several recruitment efforts in order to obtain a representative sample of the population. These include, along with the $\mathrm{N}$ of completed surveys: 1) a random sample of Montgomery County households ( $\mathrm{N}=90$ ); 2) a random sample of Virginia Tech undergraduate students ( $N=70)$; and 3) 200 local community organizations with public Facebook pages or websites $(\mathrm{N}=62)$. The representativeness of the sample was evaluated based on its similarity to 2010 Census statistics. The demographic statistics for our sample are similar to the demographics for the County.

The majority of respondents were white $(93.8 \%)$, slightly higher than the census $(87.6 \%)$. Blacks were the same as in the census $(4.0 \%)$. There were a few areas of discrepancy, such as, overrepresentation of females $(59.3 \%)$ vs the census $(48.3 \%)$, and median income $(\$ 50,000+)$ compared to the census median income $(\$ 43,229)$. The higher median income for Blacksburg and Christiansburg - which were slightly overrepresented - lifted the overall average. Similarly, on Education only $6 \%$ of our respondents completed high school or less whereas the census has over a third (36.1\%) for Montgomery County. 
Survey questions asked respondents about their interests and activities, attitudes and psychological attributes, affiliation with community groups, traditional Internet and social media use, and demographic factors. This survey drew upon validated and reliable questions from prior studies, such as the HomeNet study [28], over a decade of our prior survey research in Blacksburg and environs [29,30,31,32] and relevant civic and community studies that incorporated questions about known indicators of social and civic participation [33,34,35,36,37], [23].

With our 2012 survey data, we tested the same exogenous, mediating variables or constructs, and dependent variable that we had tested in earlier path models (2005): (1) civic, political, and social interests and activities, (2) psychological attributes, such as extroversion, political and collective efficacy, and trust, and (3) Internet use [13], [32]. We compared the results with a new dependent variable: social media use for civic purposes. Our measures used Likert scales that captured respondent's agreement on frequency scales. We created typologies by aggregating variables linked to common constructs. In order to test for interrelationships among the variables, we generated correlation coefficients and tested each of these constructs for reliability.

For our exogenous variables we relied on theory and previous studies to select and test several demographic factors that predict community involvement and civic participation [3]. These include education, extroversion and age ( $M=47.7$ years). Age and age squared are both are in the model, (although only age squared is shown). We measured extroversion with Likert-scale items of agreement regarding selfreported psychological and behavioral attributes: being talkative and outgoing (Cronbach alpha $=0.88$ ). Our mediating variables include Staying Informed, Membership, Discussion Network, and Activism (for a detailed description of constructs please see http://diggov.vt.edu/constructs).

Dependent Variables. We created two path models to test our dependent variables: Traditional Internet Use for Civic Purposes and Social Media Use for Civic Purposes. The construct Traditional Internet Use for Civic Purposes was comprised of frequency scale items that ranged from never to several times a day. Items measured respondent's civic activities on the Internet. The questions asked respondents how often in the past six months had they used the internet for the following purposes: (1) to look for information on the Town of Blacksburg website; (2) to look for information on the Montgomery County website; (3) to look for information on Blacksburg Electronic Village (BEV) website; (4) to post factual information for other citizens; (5) to express an opinion in online forums or group discussions; (6) to communicate with other residents about local concerns or issues that interest you; (7) to get national or global news; and (8) to get local news. The alpha coefficient for this scale was a respectable 0.77 .

To measure our second dependent variable, Social Media Use for Civic Purposes, we used questions adapted from a set of questions developed and used by the Pew Internet Study- Social Media and Political Engagement (2012). Participants responded to four questions that asked them if they used social network sites to receive community news or to be civically active in a group (liking or disliking a civic group, making comments about a group, and joining a community group). The measures used Likert scales that captured respondent's agreement on frequency scale 
that ranged from strongly disagree to strongly agree. The items held well together $(\alpha=0.85)$.

Statistical Analysis. Guided by our earlier research and our 2005 'civic effects of Internet Use' path model, we employed confirmatory structural equation modeling (SEM) using LISREL software to examine the explanatory power of the same variables and constructs with our 2012 survey data: education, extroversion, age (external variables), and membership, staying informed, discussion networks and activism (mediating variables) on the use of traditional internet (email and web browsing) for civic purposes $(\mathrm{N}=204)$. We also used SEM to examine the explanatory power of the same variables on the use of social media for civic purposes $(\mathrm{N}=155$, SNS users only).

To determine whether the models were a good fit for the data, we compared the relative performance of tested models across several measures: (a) the Normed Fit Index (NFI), (b) the Comparative Fit Index (CFI), (c) the Root mean Square Error of Approximation (RMSEA), and (d) the ratio of the chi-squared statistics to the degrees of freedom for the model. The CFI and NFI are both used because they both show that a value between .90 and .95 is considered marginal, above .95 is good; below .90 is considered to be a poor fitting model. We also used the ratio of the chi-squared statistics to the degrees of freedom for the model and RMSEA as measures of relative fit with lower values taken as good model performance [37].

We used SPSS to perform some ANOVA, Correlation and Multiple Regression tests to predict differences in Internet use and social media use for civic purposes, by demographic variables (education and age) and the constructs of the model. We tested additional constructs in our study, such as, collective efficacy and political efficacy, but we report only those constructs and variables that were significant.

\section{$4 \quad$ Results}

\subsection{Demographics and Use of Internet and Social Media}

As noted above, demographically our survey respondents are generally representative of Blacksburg and surrounding Montgomery County (Census Report, 2010). The average education of respondents is college graduate. The overwhelming majority $(92 \%)$ is white; more than half are female. Regarding use of the Internet and social media, the vast majority $(95 \%)$ reported using the Internet and a slightly smaller majority said they use social media $(80 \%)$. The highest percentage of heavy users of social network sites (SNS), such as Facebook and MySpace, are aged 18 to 29 years (48\%), followed by 30 to 39 year olds (20\%). Those aged 40 to 49 and 50 to 64 years old were about the same as $12 \%$ and $13 \%$, respectively. Only $7 \%$ of adults aged 65 and older report using SNS. In general our respondents are similar to those of US national surveys (Pew, 2012). However, the average SNS and Twitter user in our sample is younger and more educated than the typical SNS and Twitter user in the US based on same year (2012) statistics from studies by the Pew Internet \& American Life Project. This is important considering how demographic variables correlate with civic participation and Internet or social media use. 
Correlations Among Key Constructs. Education was positively correlated with traditional Internet use for civic purposes $(r=0.273, \mathrm{p}<0.05)$, but education was not correlated with social media use for civic purposes (given limited space we have published the correlation matrix for all variables in our path models online at http://diggov.cs.vt.edu/files/Correlation matrix.pdf). There were small to moderate positive relationships between extroversion, local group membership, political discussion network, activism, and the use of both traditional Internet and social media for civic purposes.

Respondents who were older $(r=-0.197, \mathrm{p}<0.001)$, belonged to more groups ( $r=-$ $0.226, \mathrm{p}<0.001)$, stayed more informed $(r=-0.650, \mathrm{p}<0.001)$, and had higher levels of activism $(r=-0.475, \mathrm{p}<0.001)$ also had higher measures on political discussion network. Respondents who reported using traditional Internet for civic purposes ( $r=-$ $0.387, \mathrm{p}<0.001)$ were likely to have higher measures on political discussion network compared to respondents who reported using social media for civic purposes ( $r=-$ $0.290, \mathrm{p}<0.001)$.

Results from our ANOVA tests show that younger adults, aged 18-39 years, are more likely than adults over 40 to report that compared to traditional Internet (email and web browsing), using social media is more helpful in connecting with people like themselves in the local area $(\mathrm{F}=10.147, \mathrm{p}=.00, \mathrm{M}=5.6)$. Respondents aged 18-29 years $(\mathrm{F}=3.28, \mathrm{p}=.006, \mathrm{M}=5.32)$ report that compared to using traditional Internet, using social media is more helpful in feeling connected with a diversity of people in the local area. Younger adults aged 18-39 years are more likely to use social media for civic purposes.

Path Models: Traditional Internet vs Social Media for Involvement in Local Issues. To test for differences with the path models we developed in 2005, we tested two path models with our new survey data that compare outcome measures of traditional Internet use (Figure 1) and social media use for civic purposes (Figure 2).

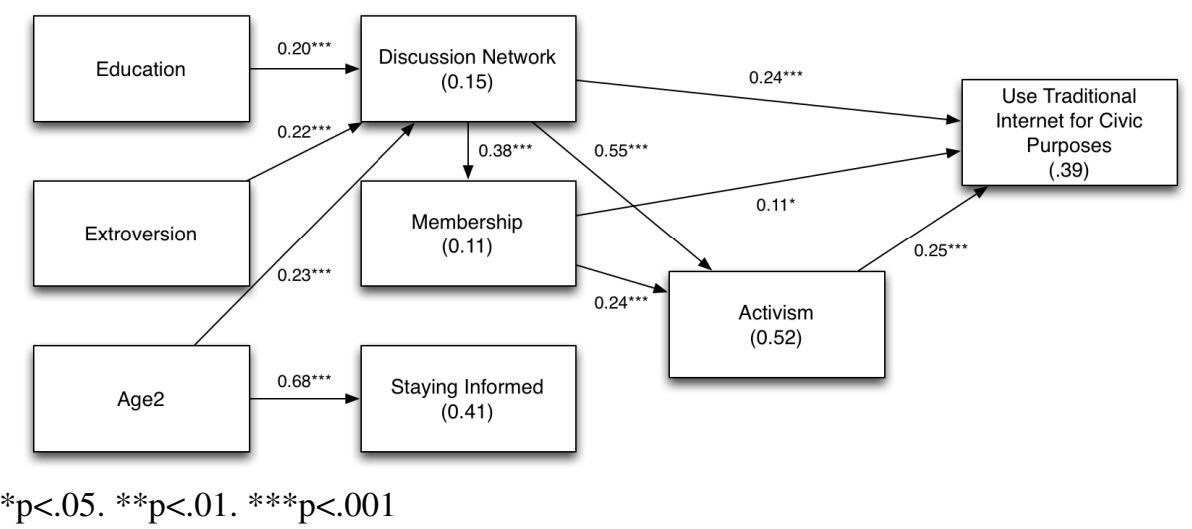

Fig. 1. Model explaining Traditional Internet Use for Civic Purposes 
We found that our key exogenous and mediating variables predict the use of both traditional Internet and social media for civic purposes. Education has a direct positive effect $(\beta=.20, \mathrm{p}<.001)$ on the use of both traditional Internet and social media for civic purposes. However, the indirect effect of education is greater for traditional Internet use $(\beta=.14, p<.01)$ than for social media use for civic purposes $(\beta=.09$, $\mathrm{p}<.05)$.

Group membership is positively associated with use of traditional Internet for civic purposes $(\beta=.11, p<.10)$, although the relationship is much stronger for the use of social media for civic purposes $(\beta=.17, \mathrm{p}<.05)$. A linear combination of political discussion network, membership and activism explained $39 \%$ of the variance in the use of traditional Internet for civic purposes (Figure 2); the same variables explained $26 \%$ of the variance in use of social media for civic purposes (Figure 2).

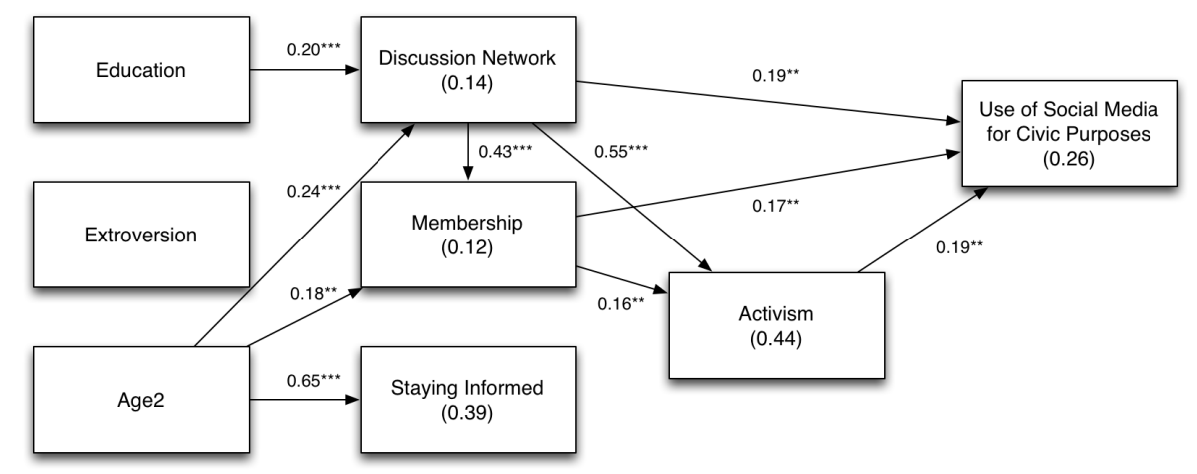

$* \mathrm{p}<.05 . * * \mathrm{p}<.01 . * * * \mathrm{p}<.001$

Fig. 2. Model Explaining Social Media Use for Civic Purposes Model

Factor loading for both models (Figures 1 and 2) was above 0.8 indicating a strong goodness of fit. Composite reliabilities of each component were uniformly higher than 0.8 while the Cronbach alpha scores were around 0.8 , thus meeting stipulated thresholds [38]. The overall fit statistics for the saturated models were good, yielding a chi-square value of 13.28 with 10 degrees of freedom $(\mathrm{RMSEA}=.04, \mathrm{CFI}=.99$, NFI $=.98$ ) for the traditional Internet use model (Figure 1) and a chi-square value of 15.86 with 12 degrees of freedom (RMSEA=.04, CFI= .99, NFI =.96) for the social media use model (Figure 2).

\section{Discussion and Conclusions}

The VTS project aimed to build an online "town square" to create a portal where citizens are able to learn about important local issues, identify and share local information with friends and family, and foster citizen deliberation about news and events in the community. As theoretical foundation for this paper identifies, 
traditional democratic theory evaluates the strength or weakness of democracies [5] by the engagement of its full range of citizens in deliberative processes and political participation behaviors. However, Dewey [10] is one of the first to explicitly articulate the need to evaluate media systems in place and whether the media characteristics foster deliberative opportunities. While this project does not aim to evaluate the quality of deliberation, it does assess use of media with different characteristics (e.g., traditional print and broadcast media, Internet, social media) and the relationships with a range of civic and political attitudes and behaviors.

Our analysis of the correlations and two path models provides a range of important insights about community members' Internet use, social media use and community involvement. We examined the strength of the relationship between education and the use of traditional Internet versus social media for civic purposes, particularly at the local level. We also analyzed new survey data in a path model that we developed earlier to try to test for differences in independent and mediating variables that explain the use of traditional Internet versus social media for civic purposes.

Our results are consistent with the preliminary 2009 Pew study finding that education is not as strongly correlated with the use of social media for civic purposes as it is with the use of traditional Internet for civic purposes. In the new path models, education has a direct positive effect on the use of both traditional Internet and social media for civic purposes. However, the indirect effect of education is greater for traditional Internet use than for social media use for civic purposes. Moreover, extroversion (outgoing and talkative), one of the defining characteristics of opinion leaders, is not significant in explaining the use of social media for civic purposes. Thus, the differences in characteristics between traditional Internet and social media appear to play an important role in fostering citizen engagement, especially by appearing to reduce the barrier related to education and seemingly engaging citizens beyond those typically identified as opinion leaders. While it is important for scholars to validate our findings in other communities and contexts, it is encouraging to report that social media extends the range and type of participant participating in civic affairs in the community.

Findings from this study appear to suggest that the communication systems, particularly features of social media, are doing a better job at serving citizens interested in engaging in civic and political affairs by engaging a broader range of citizens and reducing a significant barrier (e.g., education) to civic engagement.

Finally, political discussion network and activism, while still significant in both models, are not as strong predictors for using social media for civic purposes as they are for using traditional Internet for civic purposes. In the path model explaining social media use for civic purposes, group membership is a stronger predictor than it is for the model explaining traditional Internet use for civic purposes. These findings underscore the observation that some traditional predictors of political engagement are not as powerful in the social media environment and suggest that the social media environment broadens the characteristics of individuals engaged in civic purposes.

These findings suggest that respondents who use social media for civic purposes are not opinion leaders -- those who seemed to dominate the pattern of traditional Internet use for civic purposes. At the same time, our findings indicate the highly 
social nature of the civic involvement of people who use social media. Young adults (aged 18-39) are more likely than older adults to use social media for civic purposes. This is important because it shows that social media does lead to increased civic involvement especially for younger adults who traditionally have not been as involved in local issues as older adults -- a long standing trend that ended with the first Obama election in 2008.

The path models reported in this paper suggest that at least two groups typically underrepresented in civic and political processes, younger adults and those with lower education levels, are using social media to become more involved in their local communities. We encourage researchers to test the path models from this study in their local environment in the hope that the research community will learn more about ways communication tools, particularly affordances of social media, work to enlarge the access to and sharing of local information, encourage deliberation, and lead to increased citizen participation in civic and community affairs.

Acknowledgement. We are grateful for support from the National Science Foundation (SES-1111239) of which this work is part. We would also like to thank our collaborators Manuel Pérez-Quiñones, Naren Ramakrishnan and Joon Byoung Kim. Any errors, opinions, recommendations, findings or conclusions in this mateiral are those of the authors and do not necessarily reflect the views of the National Science Foundation.

\section{References}

1. Pew Internet \& American Life Project. Trend Data: Internet Penetration (1995-2012) (2012), http: / / pewinternet.org

2. Kavanaugh, A., Schmitz, J.: Talking in lists: The consequences of computer mediated communication on communities. Internet Research Annual 1, 250-259 (2004)

3. Hampton, K.: Neighbors Online. Pew Internet \& American Life Project (2010), http: / / pewinternet.org

4. OgilvyOne. Social Media Sells! Ogilvy \& Mather (2010), http: / /www.ogilvy.com/News / Press-Releases / November-2010Social-Media-Sells.aspx (retrieved November 1, 2010)

5. Almond, G.A., Verba, S.: The Civic Culture: Political attitudes and democracy in five nations. Princeton University Press, Princeton (1963)

6. Coleman, S., Blumler, J.G.: The Internet and Democratic Citizenship: Theory, practice and policy. Cambridge University Press, New York (2009)

7. Dahl, R.A.: Democracy and its Critics. Yale University Press, New Haven (1989)

8. Milbrath, L.W., Goel, M.L.: Political participation: How and why do people get involved in politics?, 2nd edn. Rand McNally College Pub. Co., Chicago (1977)

9. Norris, P.: Digital Divide: Civic engagement, information poverty, and the Internet worldwide. Cambridge University Press, New York (2001)

10. Smith, A., Verba, S., Brady, H., Schlozman, K.: The Internet and Civic Engagement. Pew Internet \& American Life Project (2009), http: / / pewinternet . org

11. Verba, S., Nie, N.H.: Participation in America: political democracy and social equality. Harper \& Row, New York (1972) 
12. Verba, S., Schlozman, K., Brady, H.: Voice and Equality: Civic voluntarism in American politics. Harvard University Press, Cambridge (1995)

13. Kavanaugh, A., Carroll, J.M., Rosson, M.B., Reese, D., Zin, T.T.: Participating in Civil Society: The case of networked communities. Interacting with Computers 17, 9-33 (2005)

14. Klofstad, C., McClurg, S.D., Rolfe, M.: Measurement of political discussion networks: A comparison of two "name generator" procedures. Public Opinion Quarterly 73(3), 462-483 (2009)

15. Gonzalez-Bailon, S., Kaltenbrunner, A., Banchs, R.E.: The structure of political discussion networks: A model for the analysis of online deliberation. Journal of Information Technology 25, 230-243 (2010)

16. Jacobs, L.R., Cook, F.L., Delli Carpini, M.X.: Talking Together: Public Deliberation and Political Participation in America. University of Chicago Press, Chicago (2009)

17. Kim, J., Wyatt, R., Katz, E.: News, talk, opinion, participation: the part played by conversation in deliberative democracy. Political Communication 16(4), 361-385 (1999)

18. Schudson, M.: Why conversation is not the soul of democracy. Critical Studies in Mass Communication 14, 297-309 (1997)

19. Carroll, J.M., Reese, D.: Community collective efficacy: Structure and consequences of perceived capacities in the Blacksburg Electronic Village. In: Proceedings of the Hawaii International Conference on System Sciences (HICSS-37). IEEE Computer Society, Washinton, DC (2003)

20. Carroll, J.M., Rosson, M.B., Dunlap, D., Kavanaugh, A., Schafer, W., Snook, J.: Social and Civic Participation in a Community Network. In: Kraut, R., Brynin, M., Kiesler, S. (eds.) Domesticating Information Technologies. Oxford University Press, New York (2005)

21. Hampton, K.: Grieving for lost network: Collective action in a wired suburb. The Information Society 19(5), 417-428 (2003)

22. Kavanaugh, A.: When everyone's wired: Use of the Internet for networked communities. In: Turow, J., Kavanaugh, A. (eds.) The Wired Homestead: An MIT Press Sourcebook on the Internet and the Family, pp. 423-437. MIT Press, Cambridge (2003)

23. Zúñiga, H.G.D., Veenstra, A., Vraga, E., Shah, D.: Digital Democracy: Reimagining Pathways to Political Participation. Journal of Information Technology \& Politics 7(1), 36-51 (2010)

24. Godara, J., Kavanaugh, A., Isenhour, P.: The Efficacy of Knowledge Sharing in Centralized and Self-organizing Online Communities: A Comparative Analysis of Weblogs vs Centralized Discussion Forums. In: Proceedings of the 43rd Hawaii International Conference on System Sciences (HICSS-43). IEEE Computer Society, Washington, DC (2009)

25. Kavanaugh, A., Kim, H.N., Pérez-Quiñones, M.A., Isenhour, P.: Models of local government blogging: Design trade-offs in civic engagement. In: Steinfield, C., Pentland, B., Ackerman, M., Contractor, N. (eds.) Communities and Technologies 2007, pp. 419-438. Springer, Surrey (2007)

26. Kavanaugh, A., Zin, T., Carroll, J., Schmitz, J., Pérez-Quiñones, M., Isenhour, P.: When opinion leaders blog: New forms of citizen interaction. In: Proceedings of the 7th Annual International Conference on Digital Government Research (dg.o 2006). ACM Press, New York (2006)

27. Tauro, C., Ahuja, S., Pérez-Quiñones, M.A., Kavanaugh, A., Isenhour, P.: Deliberation in the Wild: A Visualization Tool for Blog Discovery and Citizen-to-Citizen Participation. In: Proceedings of the 9th Annual International Conference on Digital Government Research (dg.o 2008). ACM Press, New York (2008) 
28. Kraut, R., Kiesler, S., Bonka, B., Cummings, J., Helgeson, V., Crawford, A.: Internet paradox revisited. Journal of Social Issues 58(1), 49-74 (2002)

29. Kavanaugh, A., Patterson, S.: The impact of community computer networking on community involvement and social capital. American Behavioral Scientist 45, 496-509 (2001)

30. Kavanaugh, A., Carroll, J.M., Rosson, M.B., Zin, T.T., Reese, D.D.: Community networks: Where offline communities meet online. Journal of Computer-Mediated Communication 10(4), article 3 (2005), http: / / jcmc.indiana. edu/vol10/issue4/kavanaugh.html

31. Kavanaugh, A., Kim, B.J., Pérez-Quiñones, M., Schmitz, J.: Net gains in political participation: Secondary effects of Internet on community. Information, Communication, and Society 11(7), 933-963 (2008)

32. Kim, B.J., Kavanaugh, A., Pérez-Quiñones, M.: Toward a Model of Political Participation among Young Adults: The role of local groups and ICT use. Paper presented at the 1st International Conference on Theory and Practice of Electronic Governance, ICEGOV (2007)

33. Brady, H.: Political Participation. In: Robinson, J., Shaver, P., Wrightsman, L. (eds.) Measures of Political Attitudes. Academic Press, San Diego (1999)

34. Edwards, J., Booth, A. (eds.): Social Participation in Urban Society. Schenkman Publishing Company, Cambridge (1973)

35. Putnam, R.D.: Bowling Alone: The collapse and revival of American community. Simon \& Schuster, New York (2000)

36. Shah, D., Kwak, N., Holbert, R.L.: Connecting" and Disconnecting with Civic Life: Patterns of Internet use and the production of social capital. Political Communication 18, 141-162 (2001)

37. Shah, D., Cho, J., Eveland Jr., W.P., Kwak, N.: Information and Expression a Digital Age. Communication Research 32(5), 531-565 (2005)

38. Nunnally, J., Bernstein, I.: Psychometric Theory, 3rd edn. McGraw Hill, New York (1994) 